\title{
A new synthetic unit hydrograph computation method based on the mass conservation principle
}

\author{
D. K. Natakusumah ${ }^{1}$, D. Harlan ${ }^{1}$ \& W. Hatmoko ${ }^{2}$ \\ ${ }^{1}$ Faculty of Civil and Environmental Engineering, \\ Institute of Technology, Bandung, Indonesia \\ ${ }^{2}$ Water Resources Research Center, Agency for Research and \\ Development, Ministry of Public Works, Bandung, Indonesia
}

\begin{abstract}
Synthetic unit hydrograph (SUH) methods are popular and play an important role in many water resources analyses of un-ganged watersheds. These methods are simple, requiring only an easy determination of watershed characteristics, such as catchment area and river length. In some cases, they may also include landuse characteristics and serve as useful tools to simulate runoff from watersheds undergoing land-use change. To develop a synthetic unit hydrograph, several synthetic unit hydrograph models such as HEC-HMS, Nakayasu, SnyderAlexeyev, SCS, and GAMA-1 are commonly used in Indonesia. In this paper, a new method for computing the synthetic unit hydrograph based on mass conservation principles is presented. This mass conserving synthetic unit hydrograph calculation procedure, called the ITB SUH calculation method, has been implemented in the development of ITB-1 and ITB-2 SUH. The unit hydrographs are synthesized by using either a simple single function (ITB-1) or using two simple functions (ITB-2) combined with automatic adjustable peak discharge factors. Some applications of the method in computing design floods of small- and medium-size catchment are presented. The results show that, although input requirements for the ITB SUH calculation method are simple and the calculation is easy, the final results agree well with other methods developed previously.
\end{abstract}

Keywords: mass conserving SUH calculation procedure, ITB SUH calculation method, ITB-1 and ITB-2 SUH, flood hydrograph, hydrology. 


\section{Introduction}

Flood estimation is one of the most important components of water resources project planning, design and operation. When long flood discharge records (more than 20 years) are available, design floods can be evaluated via a statistical analysis. However, long recorded flood discharge data are seldom availlable to determine design floods of a basin or watershed. This situation is common in many parts of the world, due to lack of gauging stations along rivers and streams. When discharge and rainfall data were not available for planning and designing water management facilities and other hydraulic structures, techniques were developed that allow generation of synthetic unit hydrographs.

The synthetic unit hydrograph method, initially proposed by Sherman in 1922, is still a widely used tool in hydrologic analysis and synthesis, especially for un-ganged watersheds. The term "synthetic" in "synthetic unit hydrograph" denotes the unit hydrograph is derived from watershed characteristics rather than rainfall-runoff data. These methods are popular and play an important role in many water resources design and analyses. These methods are simple, requiring only watershed characteristics, such as catchment area and river length, and serve as useful tools to simulate runoff from un-gagged watersheds.

This paper presents the results of the Capacity Building Research Program, funded by the Institute of Technology Bandung (ITB), Indonesia, 2010. This one-year research project was to develop a new method for calculating synthetic unit hydrographs. This mass conserving SUH calculation procedure, called ITB SUH calculation method, was initially developed by Natakusumah [1] and later implemented by Natakusumah et al. [2, 3] for developing ITB-1 and ITB-2 synthetic unit hydrographs.

\section{Synthetic unit hydrograph}

One of the most popular synthetic unit hydrograph method used is the Soil Conservation Service (SCS) curvilinear unit hydrograph. It is derived from the analysis of large numbers of natural unit hydrographs for catchments of varying size and geographic location. This method is based on the assumption that the same unit hydrograph shape applies to all catchments; only the scale differs.

Following the approach developed by SCS, we derived a unit hydrograph calculation procedure in which the unit hydrograph is dimensionless with axis of $\mathrm{q}=\mathrm{Q} / \mathrm{Q}_{\mathrm{p}}$ and $\mathrm{t}=\mathrm{T} / \mathrm{T}_{\mathrm{p}}$, $\mathrm{Q}$ equals the discharge rate at any time $\mathrm{T}$, and $\mathrm{Q}_{\mathrm{p}}$ equals the peak discharge at peak time $\mathrm{T}_{\mathrm{p}}$.

To define a complete shape of synthetic unit hydrographs, three characteristics of synthetic unit hydrographs are required. The three characteristics are: 1) basin lag $\left(T_{L}\right)$ and time to peak $\left.\left(T_{p}\right), 2\right)$ basic shape of synthetic unit hydrograph and 3 ) adjustable peak discharge $\left(\mathrm{Q}_{\mathrm{p}}\right)$ per unit rainfall depth. 


\subsection{Basin lag and time to peak}

The basin lag is an important parameter in computing unit hydrograph, but it is sometimes difficult to estimate its value in real-world situations. Many empirical equations of time lag and its relation to time to peak have been proposed in the literature [5-7]. Our proposed method is flexible in adopting time lag and time to peak formula available in the literature. In this paper, however, we compute the basin lag using a simplified Snyder formula $\left(\mathrm{L}_{\mathrm{c}}=1 / 2 \mathrm{~L}, \mathrm{n}=0.3\right)$ as follows:

$$
\mathrm{T}_{\mathrm{L}}=\mathrm{C}_{\mathrm{t}} 0.81225 \mathrm{~L}^{0.6}
$$

where:

$$
\begin{aligned}
& \mathrm{T}_{\mathrm{L}}=\text { time lag (hours) } \\
& \mathrm{C}_{\mathrm{t}}=\text { Coeff for time calibration }\left(\mathrm{C}_{\mathrm{t}}=1 \text { is standard value }\right) \\
& \mathrm{L}=\text { river length }(\mathrm{km})
\end{aligned}
$$

Furthermore, if $\mathrm{T}_{\mathrm{r}}$ is unit rainfall duration, time to peak is given as

$$
\mathrm{T}_{\mathrm{p}}=\mathrm{t}_{\mathrm{p}}+0.50 \mathrm{~T}_{\mathrm{r}}
$$

while time base is defined as

$$
\mathrm{T}_{\mathrm{b}}=\infty
$$

But in practice time base is limited to

$$
\mathrm{T}_{\mathrm{b}}=10^{*} \mathrm{~T}_{\mathrm{p}}
$$

\subsection{Basic shape of synthetic unit hydrograph}

Unlike other methods that use specific unit hydrograph shapes, the proposed method is flexible in adopting any basic shape representing unit hydrograph shape (triangular, curvilinear, etc.). Although the proposed method is applicable to any basic shape for synthetic unit hydrographs, in this research, we proposed an adjustable synthetic unit hydrograph shape synthesized by using either a simple single function (ITB-1) or two simple functions (ITB-2) as follows:

a) Single function (ITB-1)

$$
\mathrm{q}(\mathrm{t})=\exp \left(2-\mathrm{t}-\frac{1}{\mathrm{t}}\right)^{\alpha \mathrm{Cp}} \quad(\mathrm{t}>0) \quad \alpha=1.500
$$

b) Two functions (ITB-2)

- Rising limb: $\mathrm{q}(\mathrm{t})=\mathrm{t}^{\alpha} \quad(\mathrm{t}>0) \quad \alpha=1.500$

- Recession limb: $\mathrm{q}(\mathrm{t})=\exp (1-\mathrm{t})^{\beta \mathrm{Cp}} \quad(\mathrm{t}>1) \quad \beta=1.000$

where $C_{t}=$ coefficient for peak discharge calibration $\left(C_{p}=1.0\right.$ is default value). Figure 1 shows the typical shape of ITB-1 and ITB-2 synthetic unit hydrographs generate using equation (4) and (5). 


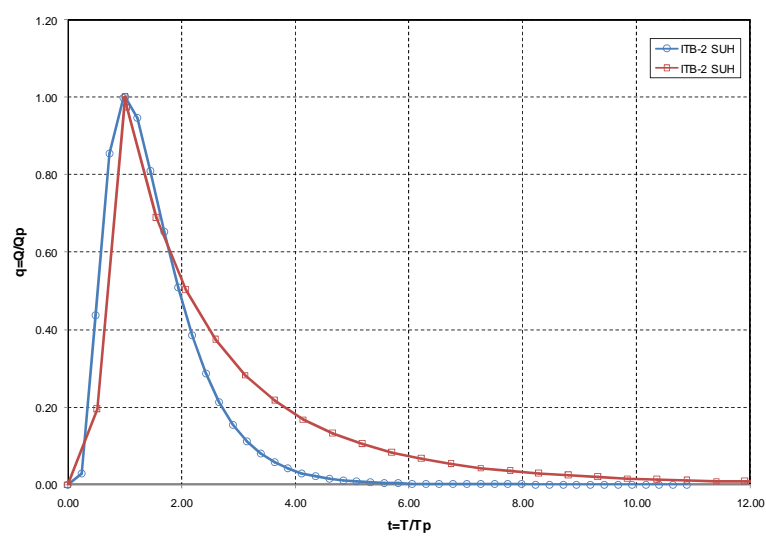

Figure 1: $\quad$ Typical shape of ITB-1 and ITB-2 synthetic unit hydrographs.

\subsection{Peak discharge of synthetic unit hydrograph}

Peak discharge of the unit hydrograph was derived by following the definition of unit hydrograph and the principle of mass conservation. Figure 2(a) and Figure 2(c) show two typical shapes of unit hydrographs (triangular and curvilinear) of a catchment generated by excess rainfall $\mathrm{R}(\mathrm{mm})$. By dividing the abscissa of the unit hydrograph by $\mathrm{T}_{\mathrm{p}}$, and dividing the ordinates and $\mathrm{Q}_{\mathrm{p}}$, we obtain the dimensionless unit hydrograph, shown in Figure 2(b) and Figure 2(d).

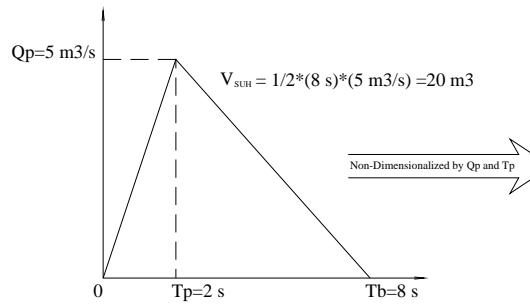

(a) Triangular SUH

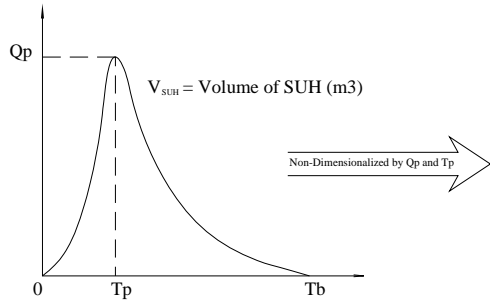

(c) Curvilinear SUH

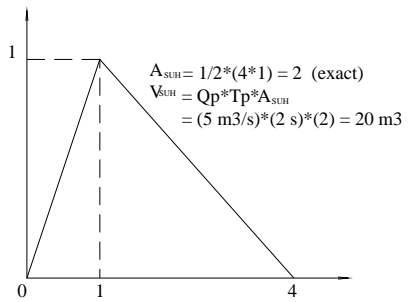

(b) Triangular SUH (dimensionless)

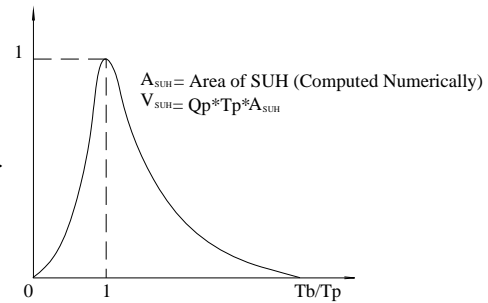

(d) Curvilinear SUH (dimensionless)

Figure 2: $\quad$ Simple method for calculating volume from unit hydrographs.

By referring to Figure 2, a simple approach for calculating unit hydrograph volume from a dimensionless unit hydrograph is as follows: 


$$
\mathrm{V}_{\mathrm{UH}}=\mathrm{Q}_{\mathrm{p}} \mathrm{T}_{\mathrm{p}} \mathrm{A}_{\mathrm{UH}}=\mathrm{Q}_{\mathrm{p}} \mathrm{T}_{\mathrm{p}} 3600 \mathrm{~A}_{\mathrm{UH}} \quad\left(\mathrm{m}^{3}\right)
$$

where $\mathrm{V}_{\mathrm{HU}}=$ volume of unit hydrograph $\left(\mathrm{m}^{3}\right), \mathrm{Q}_{\mathrm{p}}=$ peak of unit hydrograph $\left(\mathrm{m}^{3} / \mathrm{s}\right), \mathrm{A}_{\mathrm{UH}}=$ area of unit hydrograph (dimensionless). Please note that $\mathrm{A}_{\mathrm{UH}} \mathrm{can}$ be computed exactly or numerically (e.g. using trapezoidal rule).

The unit hydrograph of a catchment is defined as the direct runoff hydrograph resulting from a unit excess rainfall depth of constant intensity and uniformly distributed over the watershed $[4,5]$. Following this definition, the volume of rainfall excess can be computed as

$$
\mathrm{V}_{\mathrm{RE}}=\mathrm{A}_{\mathrm{CA}} \mathrm{R} 1000 \quad\left(\mathrm{~m}^{3}\right)
$$

where $V_{\mathrm{RE}}=$ total volume of unit excess rainfall $\left(\mathrm{m}^{3}\right), \mathrm{A}_{\mathrm{CA}}=$ area of the watershed $\left(\mathrm{km}^{2}\right)$, and $\mathrm{R}=$ unit excess rainfall depth $(\mathrm{mm})$.

By applying the principle of mass conservation (volume of unit hydrograph $=$ total volume of unit excess rainfall), we obtained

$$
\mathrm{Q}_{\mathrm{p}} \mathrm{T}_{\mathrm{p}} 3600 \mathrm{~A}_{\mathrm{UH}}=\mathrm{A}_{\mathrm{CA}} \mathrm{R} 1000
$$

Therefore the peak discharge can be written as follows:

$$
\mathrm{Q}_{\mathrm{p}}=\frac{\mathrm{R}}{3.6 \mathrm{~T}_{\mathrm{p}}} \frac{\mathrm{A}_{\mathrm{CA}}}{\mathrm{A}_{\mathrm{UH}}} \quad\left(\mathrm{m}^{3} / \mathrm{s}\right)
$$

in which $\mathrm{Q}_{\mathrm{p}}=$ the peak discharge in $\mathrm{m}^{3} / \mathrm{s}$; $\mathrm{R}=$ unit excess rainfall depth (mm); $\mathrm{A}_{\mathrm{CA}}=$ the catchment area $\left(\mathrm{km}^{2}\right) ; \mathrm{A}_{\mathrm{UH}}=$ the area of unit hydrograph (dimensionless), computed exactly or numerically (e.g. using trapezoidal rule).

\subsection{Proposed procedure for developing synthetic unit hydrographs}

The proposed procedure used for developing synthetic unit hydrographs is briefly summarized below.

Step-1 : Enter the catchment data such as catchment area $\left(\mathrm{A}_{\mathrm{CA}}\right)$, river length $(\mathrm{L})$ and unit rainfall duration ( $\mathrm{Tr}$ ).

Step-2 : Compute time lag $\left(\mathrm{T}_{\mathrm{L}}\right)$ using equation (1) or any other time lag formula available. Then compute time to peak (Tp) and time base (Tb) using equations (2) and (3).

Step-3 : Generate ITB-1 and/or ITB-2 dimensionless synthetic unit hydrograph curve using equations (4) and (5), and present them in tabular form.

Step-4 : Compute the area of the dimensionless synthetic unit hydrograph curve generated in step 3 numerically (using the trapezoidal rule).

Step-5 : Compute adjustable peak discharge of the synthetic unit hydrograph $Q_{p}$ using equation (9).

Step-6 : Generate dimensionalised synthetic unit hydrograph by multiplying the abscissa and ordinate of the dimensionless synthetic unit hydrograph obtained in step 4 by $T_{p}$ and $Q_{p}$ respectively. 
Step-7 : Compute the total volume of the synthetic unit hydrograph generated in step 6 using the trapezoidal rule. The volume of synthetic unit hydrograph must be equal to $1 \mathrm{~mm}$ (unit rainfall excess).

Step-8 : Generate the total hydrograph by performing superposition process of rainfall excess distribution for every unit rainfall duration interval.

Step-9 : Perform final check by computing the total volume of the hydrograph generated in step 8 using the trapezoidal rule. The volume of the hydrograph must be equal to the total volume of rainfall excess.

\subsection{Calibration of time to peak and peak discharge values}

Suppose, for a particular catchment, the measured unit hydrograph curve is known, and the peak discharge $\left(\mathrm{Q}_{\mathrm{p}}\right)$ as well as the time to peak $\left(\mathrm{T}_{\mathrm{p}}\right)$ are easily identifiable. The procedure used for calibrating the computed synthetic unit hydrograph is briefly summarized below.

1) If the time to peak $\left(T_{p}\right)$ of the measured and computed synthetic hydrographs are not similar, the coefficient $C_{t}$ in equation (1) should be adjusted to bring the times to peak into closer agreement. In general, $\mathrm{C}_{t}<$ 1.0 will reduce time to peak, while $C_{t}>1.0$ will increase time to peak.

2) If the peak discharges $\left(Q_{p}\right)$ of the measured and computed synthetic hydrographs are not similar, the coefficient $C_{p}$ in equation (4) and (5) should be adjusted to bring the peak discharges into closer agreement. In general $\mathrm{C}_{\mathrm{p}}<1.0$ will reduce peak discharge, while $\mathrm{C}_{\mathrm{p}}>1.0$ will increase peak discharge.

\section{Application}

In the following section, two examples application of this new method will be given. The first example demonstrates synthetic unit hydrograph calculations for a small hypothetical basin using a triangular synthetic unit hydrograph. The second example shows the implementation of ITB-1 and ITB-2 synthetic unit hydrographs for calculating flood discharge of Cibatarua river basin, a mid-size basin located in West Java, Indonesia.

\subsection{Flood hydrograph of small catchment}

The first example application of the ITB method is on a small hypothetical catchment with a catchment area of $1.2 \mathrm{~km}^{2}$, river length of $1.570 \mathrm{~km}$, and catchment slope of 0001 . To show the flexibility of the proposed method, the triangular dimensionless synthetic unit hydrograph shown in Figure 3 was used to generate a flood hydrograph due to excess rainfall of $10 \mathrm{~mm}, 70 \mathrm{~mm}$, and 30 mm (half-hour intervals). 


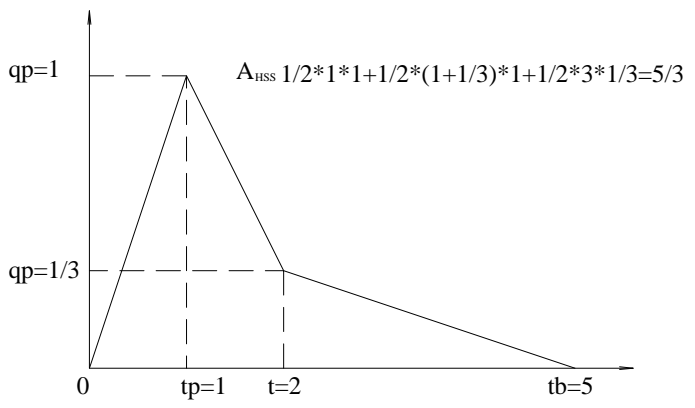

Figure 3: Triangular synthetic unit hydrograph (dimensionless).

\section{Answer}

a) Compute time to peak $\left(\mathrm{T}_{\mathrm{p}}\right)$ and time base $\left(\mathrm{T}_{\mathrm{b}}\right)$

- For a small catchment, time concentration is computed using the Kirpirch formula.

$$
\mathrm{t}_{\mathrm{c}}=0.01947 \frac{\mathrm{L}^{0.77}}{\mathrm{~S}^{0.835}}=0.01947 \frac{1575^{0.77}}{0.001^{0.835}}=80.58 \mathrm{~min}=1.34 \text { hour }
$$

- $\quad$ Time to peak $\left(\mathrm{T}_{\mathrm{p}}\right)$ and time base $\left(\mathrm{T}_{\mathrm{b}}\right)$

$\mathrm{Tp}=\frac{2}{3} \mathrm{tc}=\frac{2}{3} 1.34=0.893$ hour

$\mathrm{Tb}=\frac{8}{3} \mathrm{tp}=\frac{8}{3} 0.893=2.382$ hour

b) Compute triangular SUH

1. Compute area of triangular $\mathrm{SUH}$

$$
\begin{aligned}
\mathrm{A}_{\mathrm{HSS}}=\mathrm{A}_{1}+\mathrm{A}_{2}+\mathrm{A}_{3}=(1 / 2 * 1 * 1) & +\{1 / 2 *(1+1 / 3) * 1\} \\
& +(1 / 2 * 3 * 1 / 3)=5 / 3 \leftarrow \text { Exact value }
\end{aligned}
$$

2. Compute peak discharge of SUH

$$
\mathrm{Qp}=\frac{\mathrm{R}}{3.6 \mathrm{Tp}} \frac{\mathrm{A}_{\mathrm{CA}}}{\mathrm{A}_{\mathrm{SUH}}}=\frac{1}{3.6(0.893)} \frac{1.2}{1.667}=0.224 \mathrm{~m}^{3} / \mathrm{s}
$$

3. Dimensionalised SUH by multiplying the abscissa and ordinate of the dimensionless SUH in Figure 3 by $T_{p}$ and $Q_{p}$, and the result is shown in Figure 4. Ordinates of $\mathrm{SUH}$ between 0 and $\mathrm{T}_{\mathrm{p}}$ and between $T_{p}$ and $T_{b}$ (obtained using linear interpolation) are shown in the table 1 .

4. The superposition process of $10 \mathrm{~mm}, 70 \mathrm{~mm}$, and $30 \mathrm{~mm}$ rainfall excess (half-hour intervals), is shown in Table 1, and the final hydrograph result is shown in Figure 5. (Note the ratio of direct run 
off (DRO) and rainfall excess (RE) is less than $100 \%$ was caused by exclusion of $\mathrm{Q}_{\mathrm{p}}$ from superposition process)

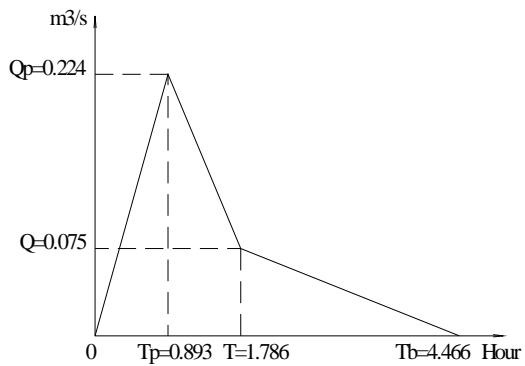

\begin{tabular}{|c|c|c|}
\hline$T$ (hour) & $\mathrm{Q}$ (m3/s) & Note \\
\hline 0.000 & 0.000 & \\
0.500 & 0.126 & \\
0.893 & 0.225 & \\
1.000 & 0.203 & $\mathrm{Tp}$ \\
1.500 & 0.123 & \\
1.786 & 0.075 & \\
2.000 & 0.069 & $2 * \mathrm{Tp}$ \\
2.500 & 0.055 & \\
3.000 & 0.041 & \\
3.500 & 0.027 & \\
4.000 & 0.013 & \\
4.466 & 0.000 & $\mathrm{~Tb}=5 \mathrm{Tp}$ \\
4.500 & 0.000 & \\
\hline
\end{tabular}

Figure 4: $\quad$ Triangular SUH (dimensionalised).

Table 1: $\quad$ Superposition of triangular SUH.

\begin{tabular}{|c|c|c|c|c|c|c|}
\hline \multirow{3}{*}{$\begin{array}{c}\text { Time } \\
\text { (Hour) }\end{array}$} & \multirow{3}{*}{$\begin{array}{l}\text { Q SUH } \\
(\mathrm{m} 3 / \mathrm{s})\end{array}$} & \multicolumn{4}{|c|}{ SUH Convolution } & \multirow{3}{*}{$\begin{array}{c}\text { Volume } \\
\text { (m3) }\end{array}$} \\
\hline & & 0.5 & 1.0 & 1.5 & Total $(\mathrm{mm}$ & \\
\hline & & 10.0 & 70.0 & 30.0 & 110.0 & \\
\hline 0.000 & 0.000 & 0.000 & & & 0.000 & 0 \\
\hline 0.500 & 0.125 & 1.253 & 0.000 & & 1.253 & 1,127 \\
\hline 1.000 & 0.202 & 2.024 & 8.769 & 0.000 & 10.792 & 10,841 \\
\hline 1.500 & 0.122 & 1.224 & 14.167 & 3.758 & 19.149 & 26,948 \\
\hline 2.000 & 0.069 & 0.687 & 8.571 & 6.072 & 15.330 & 31,031 \\
\hline 2.500 & 0.055 & 0.550 & 4.811 & 3.673 & 9.034 & 21,927 \\
\hline 3.000 & 0.041 & 0.412 & 3.849 & 2.062 & 6.323 & 13,821 \\
\hline 3.500 & 0.027 & 0.275 & 2.886 & 1.649 & 4.811 & 10,020 \\
\hline 4.000 & 0.014 & 0.137 & 1.924 & 1.237 & 3.299 & 7,299 \\
\hline 4.500 & 0.000 & 0.000 & 0.962 & 0.825 & 1.787 & 4,577 \\
\hline 5.000 & & 0.000 & 0.000 & 0.412 & 0.412 & 1,979 \\
\hline 5.500 & & & 0.000 & 0.000 & 0.000 & 371 \\
\hline & & & & \multirow{4}{*}{\multicolumn{2}{|c|}{$\begin{array}{l}\text { Total Volum }(\mathrm{m} 3) \\
\text { C. Area }(\mathrm{km} 2) \\
\text { DRO }(\mathrm{mm}) \\
\text { DRO/RE }(\%) \\
\end{array}$}} & 129,570 \\
\hline & & & & & & 1.200 \\
\hline & & & & & & $\begin{array}{l}107.98 \\
98.16 \%\end{array}$ \\
\hline & & & & & & \\
\hline
\end{tabular}

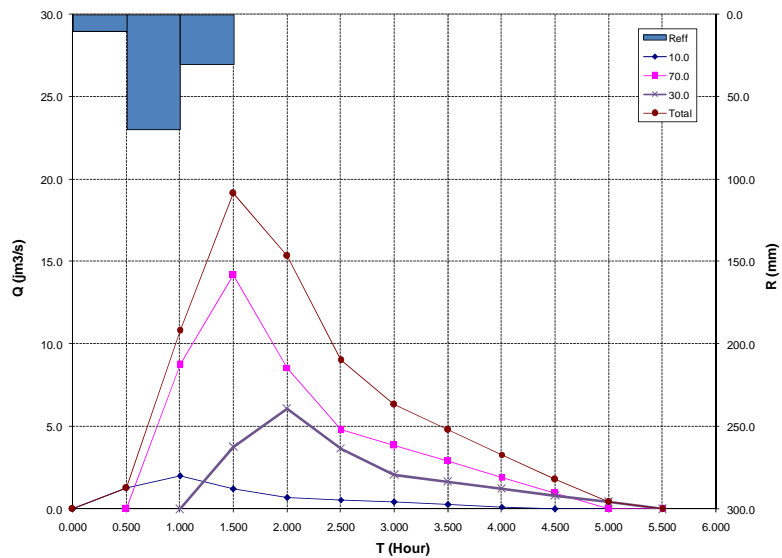

Figure 5: $\quad$ Superposition of triangular SUHs to form a total hydrograph. 


\subsection{Flood hydrograph of Cibatarua watershed}

The second example application of ITB methods is the computation of the flood hydrograph of the Cibatarua river basin. Cibatarua river has catchment area of $56.920 \mathrm{~km}^{2}$, river length of $12.150 \mathrm{~km}$, and catchment slope of 008 . In this example, time lag for ITB-1 SUH was calculated using the Snyder method, while ITB-2 time lag was calculated using the Nakayasu formula. The calculation procedures for generating ITB-1 and ITB-2 SUH are shown in Table 3 and Table 4.

Furthermore, the incremental rainfall excess shown in Table 2 used to generate the total hydrographs, using the superposition process shown in Table 5 and Table 6 . The resulting total hydrographs were compared with the results other methods shown in Figure 6. This figure shows that the results of HSS ITB1 are close to those of the Snyder-Alexeyev and HEC-HMS results, while the ITB HSS-2 (with $\alpha=1.50$ and non-default $\beta=0.72$ ) are close to the Nakayasu results ( $\alpha=3.00$ for Nakayasu).

Table 2: $\quad$ Rainfall excess distribution.

\begin{tabular}{|c|c|}
\hline Time $(\mathrm{Hr})$ & $\mathrm{RE}(\mathrm{mm})$ \\
\hline 1.000 & 55.400 \\
2.000 & 16.100 \\
3.000 & 11.700 \\
4.000 & 9.200 \\
5.000 & 7.200 \\
6.000 & 5.700 \\
\hline
\end{tabular}

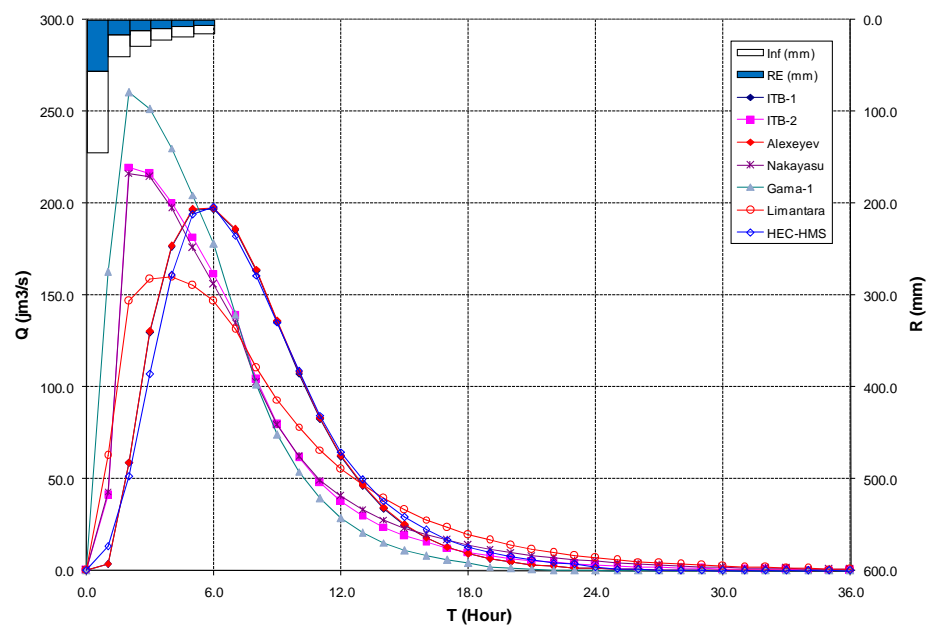

Figure 6: Comparison results of ITB HSS-and HSS ITB-2 with the results of Snyder-Alexeyev, Nakayasu, Limantara, GAMA-1, and HECHMS. 
Table 3: ITB-1 SUH calculation for Cibatarua Basin (time lag Snyder).
Table 4:

ITB-2 SUH calculation for Cibatarua Basin (time lag Nakayasu).

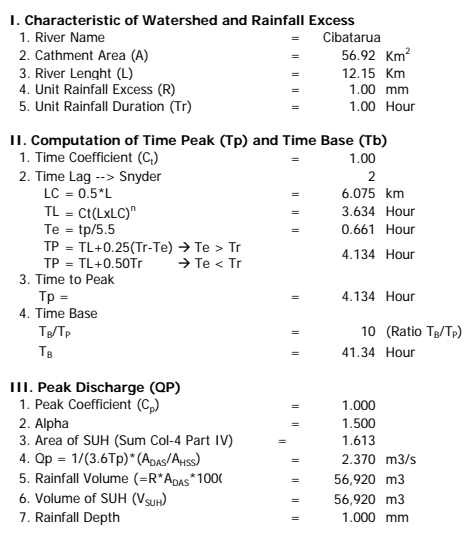

IV. Computation of ITB-1 SUH :

\begin{tabular}{|c|c|c|c|c|c|}
\hline \multirow{3}{*}{$\begin{array}{c}\mathrm{T}^{\mathrm{T}} \\
\text { (hour) } \\
(1)\end{array}$} & \multicolumn{3}{|c|}{ SUH (dimensionless) } & \multicolumn{2}{|c|}{ SUH (dimensionalised) } \\
\hline & $\mathrm{t}=\mathrm{T} / \mathrm{Tp}$ & $q=Q / Q p$ & $\mathrm{~A}$ & $Q(\mathrm{~m} 3 / \mathrm{s})$ & \\
\hline & $(2)$ & (3) & $(4)$ & $(5)$ & $(6)$ \\
\hline 0.00 & 0.00000 & 0.00000 & 0.00000 & 0.00000 & 0.0000 \\
\hline 1.00 & 0.24187 & 0.02831 & 0.00342 & 0.06711 & 120.7954 \\
\hline 2.00 & 0.48374 & 0.43760 & 0.05635 & 1.03725 & 1987.8489 \\
\hline 3.00 & 0.72561 & 0.85587 & 0.15643 & 2.02866 & 5518.6460 \\
\hline 4.00 & 0.96748 & 0.99836 & 0.22424 & 2.36641 & 7911.1317 \\
\hline 4.13 & 1.00000 & 1.00000 & 0.03249 & 2.37029 & 1146.1919 \\
\hline 5.00 & 1.20936 & 0.94709 & 0.20382 & 2.24488 & 7190.5209 \\
\hline 6.00 & 1.45123 & 0.81022 & 0.21252 & 1.92046 & 7497.6064 \\
\hline 7.00 & 1.69310 & 0.65338 & 0.17700 & 1.54870 & 6244.4931 \\
\hline 8.00 & 1.93497 & 0.50780 & 0.14043 & 1.20364 & 4954.2235 \\
\hline 9.00 & 2.17684 & 0.38507 & 0.10798 & 0.91273 & 3809.4690 \\
\hline 10.00 & 2.41871 & 0.28701 & 0.08128 & 0.68030 & 2867.4530 \\
\hline 11.00 & 2.66058 & 0.21126 & 0.06026 & 0.50075 & 2125.8966 \\
\hline 12.00 & 2.90245 & 0.15405 & 0.04418 & 0.36514 & 1558.6070 \\
\hline 13.00 & 3.14432 & 0.11152 & 0.03212 & 0.26434 & 1133.0651 \\
\hline 14.00 & 3.38620 & 0.08028 & 0.02320 & 0.19028 & 818.3158 \\
\hline 15.00 & 3.62807 & 0.05752 & 0.01667 & 0.13635 & 587.9357 \\
\hline 16.00 & 3.86994 & 0.04107 & 0.01192 & 0.09734 & 420.6509 \\
\hline 17.00 & 4.11181 & 0.02923 & 0.00850 & 0.06929 & 299.9368 \\
\hline 18.00 & 4.35368 & 0.02075 & 0.00604 & 0.04919 & 213.2601 \\
\hline 19.00 & 4.59555 & 0.01470 & 0.00429 & 0.03485 & 151.2732 \\
\hline 20.00 & 4.83742 & 0.01040 & 0.00304 & 0.02464 & 107.0893 \\
\hline 21.00 & 5.07929 & 0.00734 & 0.00215 & 0.01740 & 75.6814 \\
\hline 22.00 & 5.32116 & 0.00518 & 0.00151 & 0.01227 & 53.4067 \\
\hline 23.00 & 5.56303 & 0.00365 & 0.00107 & 0.00864 & 37.6401 \\
\hline 24.00 & 5.80491 & 0.00257 & 0.00075 & 0.00608 & 26.4988 \\
\hline 25.00 & 6.04678 & 0.00180 & 0.00053 & 0.00427 & 18.6371 \\
\hline 26.00 & 6.28865 & 0.00127 & 0.00037 & 0.00300 & 13.0967 \\
\hline 27.00 & 6.53052 & 0.00089 & 0.00026 & 0.00211 & 9.1963 \\
\hline 28.00 & 6.77239 & 0.00062 & 0.00018 & 0.00148 & 6.4531 \\
\hline 29.00 & 7.01426 & 0.00044 & 0.00013 & 0.00104 & 4.5255 \\
\hline 30.00 & 7.25613 & 0.00031 & 0.00009 & 0.00073 & 3.1720 \\
\hline 31.00 & 7.49800 & 0.00021 & 0.00006 & 0.00051 & 2.2222 \\
\hline 32.00 & 7.73987 & 0.00015 & 0.00004 & 0.00036 & 1.5561 \\
\hline 33.00 & 7.98175 & 0.00011 & 0.00003 & 0.00025 & 1.0892 \\
\hline 34.00 & 8.22362 & 0.00007 & 0.00002 & 0.00017 & 0.7621 \\
\hline 35.00 & 8.46549 & 0.00005 & 0.00002 & 0.00012 & 0.5331 \\
\hline 36.00 & 8.70736 & 0.00004 & 0.00001 & 0.00009 & 0.3728 \\
\hline 37.00 & 8.94923 & 0.00003 & 0.00001 & 0.00006 & 0.2606 \\
\hline 38.00 & 9.19110 & 0.00002 & 0.00001 & 0.00004 & 0.1821 \\
\hline 39.00 & 9.43297 & 0.00001 & 0.00000 & 0.00003 & 0.1273 \\
\hline 40.00 & 9.67484 & 0.00001 & 0.00000 & 0.00002 & 0.0889 \\
\hline 41.00 & 9.91671 & 0.00001 & 0.00000 & 0.00001 & 0.0621 \\
\hline 42.00 & 10.15859 & 0.00000 & 0.00000 & 0.00000 & 0.0255 \\
\hline 43.00 & 10.40046 & 0.00000 & 0.00000 & 0.00000 & 0.0000 \\
\hline 44.00 & 10.64233 & 0.00000 & 0.00000 & 0.00000 & 0.0000 \\
\hline \multirow[t]{3}{*}{45.00} & 10.88420 & 0.00000 & 0.00000 & 0.00000 & 0.0000 \\
\hline & & Area SUH & 1.6134085 & Vol (m3) & 56920.000 \\
\hline & & & & RO $(\mathrm{mm})$ & 1.000 \\
\hline \multicolumn{6}{|c|}{ Remarks } \\
\hline Col-1 & \multicolumn{5}{|c|}{ Given Time Interval (Hour) $\rightarrow T_{i}=T_{i-1}+T r$} \\
\hline $\mathrm{Col}-2$ & \\
\hline Col-3 & \multicolumn{2}{|c|}{ Dimensionless Ordinate $q=Q / Q p$ from ITB- 1 Equation Curve } & & & \\
\hline Col-4 & \multicolumn{5}{|c|}{ Area of SUH $\rightarrow A_{i}=1 / 2 \times\left(t_{i}-t_{i-1}\right) \times\left(q_{i}+q_{i-1}\right)$ (dimensionless) } \\
\hline & \multicolumn{5}{|c|}{ Sum of Column-4 = $\mathrm{A}_{\text {SUH }}$ (Important for Computing Qp) } \\
\hline Col-5 & \multicolumn{5}{|c|}{ Dimensionalised $Q \mathrm{Qi} \rightarrow \mathrm{Q}_{\mathrm{i}}=\mathrm{q}_{\mathrm{i}} \times \mathrm{Qp}($ Kolom $3 \times \mathrm{Qp})$} \\
\hline Col-6 & \multicolumn{5}{|c|}{ Area of SUH $(m 3) \rightarrow A_{i}=1 / 2 \times 3600 \times\left(T_{i-} T_{i-1}\right) \times\left(Q_{i}+Q_{i-1}\right)$} \\
\hline & & & & & \\
\hline
\end{tabular}

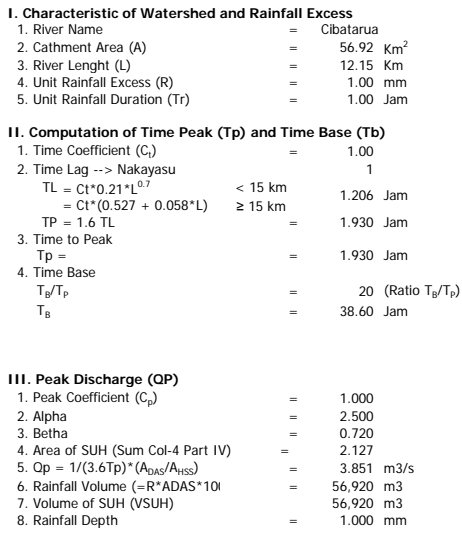

IV. Computation of ITB-2 SUH :

\begin{tabular}{|c|c|c|c|c|c|}
\hline \multirow{3}{*}{ 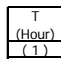 } & \multicolumn{3}{|c|}{ SUH (dimensionless) } & \multicolumn{2}{|c|}{ SUH (dimensionalised) } \\
\hline & $t=T / T p$ & $q=Q / Q p$ & A & $Q(\mathrm{~m} 3 / \mathrm{s})$ & $\mathrm{V}(\mathrm{m} 3)$ \\
\hline & $(2)$ & (3) & $(4)$ & (5) & $(6)$ \\
\hline & 0.00000 & 0.00000 & 0.00000 & 0.00000 & 0.0000 \\
\hline 1.00 & 0.51815 & 0.19326 & 0.05007 & 0.74431 & 1339.7578 \\
\hline 1.93 & 1.00000 & 1.00000 & 0.28749 & 3.85133 & 7692.5589 \\
\hline 2.00 & 1.03630 & 0.97433 & 0.03584 & 3.75245 & 958.9665 \\
\hline 3.00 & 1.55446 & 0.68809 & 0.43069 & 2.65004 & 11524.4951 \\
\hline 4.00 & 2.07261 & 0.50156 & 0.30821 & 1.93169 & 8247.1234 \\
\hline 5.00 & 2.59076 & 0.37360 & 0.22673 & 1.43885 & 6066.9674 \\
\hline 6.00 & 3.10891 & 0.28281 & 0.17006 & 1.08921 & 4550.4997 \\
\hline 7.00 & 3.62707 & 0.21684 & 0.12945 & 0.83512 & 3463.7900 \\
\hline 8.00 & 4.14522 & 0.16800 & 0.09970 & 0.64703 & 2667.8759 \\
\hline 9.00 & 4.66337 & 0.13132 & 0.07755 & 0.50574 & 2074.9949 \\
\hline 10.00 & 5.18152 & 0.10342 & 0.06081 & 0.39830 & 1627.2813 \\
\hline 11.00 & 5.69967 & 0.08199 & 0.04804 & 0.31577 & 1285.3325 \\
\hline 12.00 & 6.21783 & 0.06538 & 0.03818 & 0.25180 & 1021.6342 \\
\hline 13.00 & 6.73598 & 0.05241 & 0.03052 & 0.20185 & 816.5789 \\
\hline 14.00 & 7.25413 & 0.04221 & 0.02451 & 0.16257 & 655.9566 \\
\hline 15.00 & 7.77228 & 0.03414 & 0.01978 & 0.13150 & 529.3221 \\
\hline 16.00 & 8.29043 & 0.02773 & 0.01603 & 0.10678 & 428.9030 \\
\hline 17.00 & 8.80859 & 0.02260 & 0.01304 & 0.08703 & 348.8544 \\
\hline 18.00 & 9.32674 & 0.01848 & 0.01064 & 0.07116 & 284.7394 \\
\hline 19.00 & 9.84489 & 0.01516 & 0.00871 & 0.05837 & 233.1623 \\
\hline 20.00 & 10.36304 & 0.01247 & 0.00716 & 0.04802 & 191.5045 \\
\hline 21.00 & 10.88120 & 0.01028 & 0.00589 & 0.03961 & 157.7335 \\
\hline 22.00 & 11.39935 & 0.00851 & 0.00487 & 0.03276 & 130.2616 \\
\hline 23.00 & 11.91750 & 0.00705 & 0.00403 & 0.02716 & 107.8422 \\
\hline 24.00 & 12.43565 & 0.00586 & 0.00334 & 0.02256 & 89.4909 \\
\hline 25.00 & 12.95380 & 0.00488 & 0.00278 & 0.01879 & 74.4273 \\
\hline 26.00 & 13.47196 & 0.00407 & 0.00232 & 0.01567 & 62.0294 \\
\hline 27.00 & 13.99011 & 0.00340 & 0.00194 & 0.01310 & 51.8000 \\
\hline 28.00 & 14.50826 & 0.00285 & 0.00162 & 0.01097 & 43.3398 \\
\hline 29.00 & 15.02641 & 0.00239 & 0.00136 & 0.00921 & 36.3272 \\
\hline 30.00 & 15.54457 & 0.00201 & 0.00114 & 0.00774 & 30.5019 \\
\hline 31.00 & 16.06272 & 0.00169 & 0.00096 & 0.00651 & 25.6532 \\
\hline 32.00 & 16.58087 & 0.00143 & 0.00081 & 0.00549 & 21.6095 \\
\hline 33.00 & 17.09902 & 0.00120 & 0.00068 & 0.00464 & 18.2309 \\
\hline 34.00 & 17.61717 & 0.00102 & 0.00058 & 0.00392 & 15.4030 \\
\hline 35.00 & 18.13533 & 0.00086 & 0.00049 & 0.00332 & 13.0321 \\
\hline 36.00 & 18.65348 & 0.00073 & 0.00041 & 0.00281 & 11.0411 \\
\hline 37.00 & 19.17163 & 0.00062 & 0.00035 & 0.00239 & 9.3664 \\
\hline 38.00 & 19.68978 & 0.00053 & 0.00030 & 0.00203 & 7.9558 \\
\hline 39.00 & 20.20793 & 0.00000 & 0.00014 & 0.00000 & 3.6553 \\
\hline 40.00 & 20.72609 & 0.00000 & 0.00000 & 0.00000 & 0.0000 \\
\hline 41.00 & 21.24424 & 0.00000 & 0.00000 & 0.00000 & 0.0000 \\
\hline 42.00 & 21.76239 & 0.00000 & 0.00000 & 0.00000 & 0.0000 \\
\hline 43.00 & 22.28054 & 0.00000 & 0.00000 & 0.00000 & 0.0000 \\
\hline 44.00 & 22.79870 & 0.00000 & 0.00000 & 0.00000 & 0.0000 \\
\hline \multirow[t]{2}{*}{45.00} & 23.31685 & 0.00000 & 0.00000 & 0.00000 & 0.0000 \\
\hline & & Area SUH & 2.1272046 & Vol (m3) & 56920.000 \\
\hline & & & & & \\
\hline \multicolumn{6}{|c|}{ Remarks } \\
\hline Col-1 & \multicolumn{5}{|c|}{ : Given Time Interval (Hour) $\rightarrow T_{i}=T_{i-1}+T r$} \\
\hline & \multirow{2}{*}{\multicolumn{5}{|c|}{$\begin{array}{l}\text { Dimensionless Time } t=T / T p \rightarrow \text { Kolom- } 1 / T p \\
\text { Dimensionless Ordinate } q=Q / Q p \text { from ITB-2 Equation Curve }\end{array}$}} \\
\hline $\mathrm{Col}-3$ & & & & & \\
\hline Col-4 & \multicolumn{5}{|c|}{ : Area of SUH $\rightarrow A_{i}=1 / 2 \times\left(t_{i}-t_{i-1}\right) \times\left(q_{i}+q_{i-1}\right)$ (dimensionless) } \\
\hline & \multicolumn{5}{|c|}{ : Sum of Column-4 = $A_{\text {SUH }}$ (Important for Computing QP) } \\
\hline Col-5 & \multicolumn{5}{|c|}{ : Dimensionalised $Q i \rightarrow Q_{i}=q_{i} \times Q p \quad($ Kolom $3 \times Q p)$} \\
\hline Col-6 & \multirow{2}{*}{\multicolumn{5}{|c|}{ : Area of SUH $(\mathrm{m} 3) \rightarrow A_{i}=1 / 2 \times 3600 \times\left(T_{i}-T_{i-1}\right) \times\left(Q_{i}+Q_{i-1}\right)$}} \\
\hline & & & & & \\
\hline
\end{tabular}


Table 5: Superposition of ITB-1 Table 6: Superposition of ITB-2 UH. UH.

\begin{tabular}{|c|c|c|c|c|c|c|c|c|c|}
\hline \multirow{2}{*}{$\begin{array}{c}\text { Time } \\
\text { (hour) }\end{array}$} & \multirow{2}{*}{$\begin{array}{l}\text { ITB-1 } \\
\text { SUH }\end{array}$} & \multicolumn{6}{|c|}{ Hydrograph C } & \multirow{2}{*}{ Total } & \multirow{2}{*}{$\begin{array}{l}\text { Vol Hyd } \\
\text { (m3) }\end{array}$} \\
\hline & & $\frac{1}{55.40}$ & $\frac{2}{1610}$ & 3 & 4 & 5 & $\begin{array}{c}6 \\
577\end{array}$ & & \\
\hline 0.0 & 0.00 & 0.00 & & & & & & 0.00 & 0 \\
\hline 1.00 & 0.07 & 3.72 & 0.00 & & & & & 3.72 & 6692 \\
\hline 2.00 & 1.04 & 57.46 & 1.08 & 0.00 & & & & 58.54 & 112072 \\
\hline 3.00 & 2.03 & 112.39 & 16.70 & 0.79 & 0.00 & & & 129.87 & 339151 \\
\hline 4.00 & 2.37 & 131.10 & 32.66 & 12.14 & 0.62 & 0.00 & & 176.51 & 551496 \\
\hline 5.00 & 2.24 & 124.37 & 38.10 & 23.74 & 9.54 & 0.48 & 0.00 & 196.23 & 670933 \\
\hline 6.00 & 1.92 & 106.39 & 36.14 & 27.69 & 18.66 & 7.47 & 0.38 & 196.74 & 707335 \\
\hline 7.00 & 1.55 & 85.80 & 30.92 & 26.27 & 21.77 & 14.61 & 5.91 & 185.27 & 687617 \\
\hline 8.00 & 1.20 & 66.68 & 24.93 & 22.47 & 20.65 & 17.04 & 11.56 & 163.34 & 627502 \\
\hline 9.00 & 0.91 & 50.57 & 19.38 & 18.12 & 17.67 & 16.16 & 13.49 & 135.38 & 537702 \\
\hline 10.00 & 0.68 & 37.69 & 14.69 & 14.08 & 14.25 & 13.83 & 12.80 & 107.34 & 436898 \\
\hline 11.00 & 0.50 & 27.74 & 10.95 & 10.68 & 11.07 & 11.15 & 10.95 & 82.54 & 341787 \\
\hline 12.00 & 0.37 & 20.23 & 8.06 & 7.96 & 8.40 & 8.67 & 8.83 & 62.14 & 260434 \\
\hline 13.00 & 0.26 & 14.64 & 5.88 & 5.86 & 6.26 & 6.57 & 6.86 & 46.07 & 194786 \\
\hline 14.00 & 0.19 & 10.54 & 4.26 & 4.27 & 4.61 & 4.90 & 5.20 & 33.78 & 143731 \\
\hline 15.00 & 0.14 & 7.55 & 3.06 & 3.09 & 3.36 & 3.61 & 3.88 & 24.55 & 104994 \\
\hline 16.00 & 0.10 & 5.39 & 2.20 & 2.23 & 2.43 & 2.63 & 2.85 & 17.73 & 76108 \\
\hline 17.00 & 0.07 & 3.84 & 1.57 & 1.60 & 1.75 & 1.90 & 2.08 & 12.74 & 54838 \\
\hline 18.00 & 0.05 & 2.73 & 1.12 & 1.14 & 1.25 & 1.37 & 1.51 & 9.11 & 39325 \\
\hline 19.00 & 0.03 & 1.93 & 0.79 & 0.81 & 0.90 & 0.98 & 1.08 & 6.50 & 28091 \\
\hline 20.00 & 0.02 & 1.37 & 0.56 & 0.58 & 0.64 & 0.70 & 0.78 & 4.62 & 20003 \\
\hline 21.00 & 0.02 & 0.96 & 0.40 & 0.41 & 0.45 & 0.50 & 0.55 & 3.27 & 14206 \\
\hline 22.00 & 0.01 & 0.68 & 0.28 & 0.29 & 0.32 & 0.35 & 0.39 & 2.32 & 10067 \\
\hline 23.00 & 0.01 & 0.48 & 0.20 & 0.20 & 0.23 & 0.25 & 0.28 & 1.64 & 7121 \\
\hline 24.00 & 0.01 & 0.34 & 0.14 & 0.14 & 0.16 & 0.18 & 0.20 & 1.16 & 5028 \\
\hline 25.00 & 0.00 & 0.24 & 0.10 & 0.10 & 0.11 & 0.13 & 0.14 & 0.81 & 3546 \\
\hline 26.00 & 0.00 & 0.17 & 0.07 & 0.07 & 0.08 & 0.09 & 0.10 & 0.57 & 2498 \\
\hline 27.00 & 0.00 & 0.12 & 0.05 & 0.05 & 0.06 & 0.06 & 0.07 & & 1758 \\
\hline 28.00 & 0.00 & 0.08 & 0.03 & 0.04 & 0.04 & 0.04 & 0.05 & 0.28 & 1236 \\
\hline 29.00 & 0.00 & 0.06 & 0.02 & 0.02 & 0.03 & 0.03 & 0.03 & 0.20 & 868 \\
\hline 30.00 & 0.00 & 0.04 & 0.02 & 0.02 & 0.02 & 0.02 & 0.02 & 0.14 & 609 \\
\hline 31.00 & 0.00 & 0.03 & 0.01 & 0.01 & 0.01 & 0.02 & 0.02 & & 427 \\
\hline 32.00 & 0.00 & 0.02 & 0.01 & 0.01 & 0.01 & 0.01 & 0.01 & 0.07 & 300 \\
\hline 33.00 & 0.00 & 0.01 & 0.01 & 0.01 & 0.01 & 0.01 & 0.01 & 0.05 & 210 \\
\hline 34.00 & 0.00 & 0.01 & 0.00 & 0.00 & 0.00 & 0.01 & 0.01 & 0.03 & 147 \\
\hline 35.00 & 0.00 & 0.01 & 0.00 & 0.00 & 0.00 & 0.00 & 0.00 & 0.0 & 103 \\
\hline 36.00 & 0.00 & 0.00 & 0.00 & 0.00 & 0.00 & 0.00 & 0.00 & 0.02 & 72 \\
\hline 37.00 & 0.00 & 0.00 & 0.00 & 0.00 & 0.00 & 0.00 & 0.00 & 0.01 & 50 \\
\hline 38.00 & 0.00 & 0.00 & 0.00 & 0.00 & 0.00 & 0.00 & 0.00 & 0.01 & 35 \\
\hline 39.00 & 0.00 & 0.00 & 0.00 & 0.00 & 0.00 & 0.00 & 0.00 & 0.01 & 25 \\
\hline 40.00 & 0.00 & 0.00 & 0.00 & 0.00 & 0.00 & 0.00 & 0.00 & 0.00 & 17 \\
\hline 41.00 & 0.00 & 0.00 & 0.00 & 0.00 & 0.00 & 0.00 & 0.00 & & 12 \\
\hline 42.00 & 0.00 & 0.00 & 0.00 & 0.00 & 0.00 & 0.00 & 0.00 & 0.00 & 7 \\
\hline 43.00 & 0.00 & 0.00 & 0.00 & 0.00 & 0.00 & 0.00 & 0.00 & 0.00 & 4 \\
\hline 44.00 & 0.00 & 0.00 & 0.00 & 0.00 & 0.00 & 0.00 & 0.00 & 0.00 & 2 \\
\hline 45.00 & 0.00 & 0.00 & 0.00 & 0.00 & 0.00 & 0.00 & 0.00 & 0.00 & 1 \\
\hline 46.00 & 0.00 & 0.00 & 0.00 & 0.00 & 0.00 & 0.00 & 0.00 & 0.00 & 1 \\
\hline 47.00 & 0.00 & 0.00 & 0.00 & 0.00 & 0.00 & 0.00 & 0.00 & & 0 \\
\hline 48.00 & 0.00 & 0.00 & 0.00 & 0.00 & 0.00 & 0.00 & 0.00 & & 0 \\
\hline 49.00 & 0.00 & 0.00 & 0.00 & 0.00 & 0.00 & 0.00 & 0.00 & 0.00 & 0 \\
\hline 50.00 & 0.00 & 0.00 & 0.00 & 0.00 & 0.00 & 0.00 & 0.00 & 0.00 & 0 \\
\hline & & & & & & Vol Hyc & & $\mathrm{m} 3$ & $6 \mathrm{E}+06$ \\
\hline & & & & & & & & $\mathrm{km} 2$ & $\begin{array}{c}56.92 \\
\end{array}$ \\
\hline & & & & & & Direct & & $\mathrm{mm}$ & 105.23 \\
\hline & & & & & & Rasio [ & & & $99.9 \%$ \\
\hline
\end{tabular}

\begin{tabular}{|c|c|c|c|c|c|c|c|c|c|}
\hline \multirow{2}{*}{$\begin{array}{c}\text { Time } \\
\text { (hour) }\end{array}$} & \multirow{3}{*}{$\begin{array}{l}\text { ITB-2 } \\
\text { SUH }\end{array}$} & \multicolumn{6}{|c|}{ Hydrograph Convolution } & \multirow[b]{2}{*}{ Total } & \multirow{3}{*}{$\begin{array}{l}\text { Vol Hyd } \\
\text { (m3) }\end{array}$} \\
\hline & & 1 & 2 & & 4 & 5 & 6 & & \\
\hline 00 & & 55.40 & 16.10 & 11.70 & 9.20 & 7.20 & 5.70 & .05 .300 & \\
\hline & 0.00 & 0.00 & & & & & & 0.00 & 0 \\
\hline 1.00 & 0.74 & 41.23 & 0.00 & & & & & 41.23 & 74223 \\
\hline 2.00 & 3.75 & 207.9 & 11.98 & 0.00 & & & & 219.87 & 469987 \\
\hline 3.00 & 2.65 & 146.81 & 60.41 & 8.71 & 0.00 & & & 215.94 & 784448 \\
\hline 4.00 & 1.93 & 107.02 & 42.67 & 43.90 & 6.85 & 0.00 & & 200.4 & 749463 \\
\hline 5.00 & 1.44 & 79.71 & 31.10 & 31.01 & 34.52 & 5.36 & 0.00 & 181.70 & 687838 \\
\hline 6.00 & 1.09 & 60.34 & 23.17 & 22.60 & 24.38 & 27.02 & 4.24 & 161.75 & 618207 \\
\hline 7.00 & 0.84 & 46.27 & 17.54 & 16.83 & 17.77 & 19.08 & 21.39 & 138.88 & 541127 \\
\hline 8.00 & 0.65 & 35.85 & 13.45 & 12.74 & 13.24 & 13.91 & 15.11 & 104.29 & 437693 \\
\hline 9.00 & 0.51 & 28.02 & 10.42 & 9.77 & 10.02 & 10.36 & 11.01 & 79.60 & 330989 \\
\hline 10.00 & 0.40 & 22.07 & 8.14 & 7.57 & 7.68 & 7.84 & 8.20 & 61.51 & 253985 \\
\hline 11.00 & 0.32 & 17.49 & 6.41 & 5.92 & 5.95 & 6.01 & 6.21 & 48.00 & 197106 \\
\hline 12.00 & 0.25 & 13.95 & 5.08 & 4.66 & 4.65 & 4.66 & 4.76 & 37.77 & 154374 \\
\hline 13.00 & 0.20 & 11.18 & 4.05 & 3.69 & 3.66 & 3.64 & 3.69 & 29.92 & 121843 \\
\hline 14.00 & 0.16 & 9.01 & 3.25 & 2.95 & 2.91 & 2.87 & 2.88 & 23.86 & 96809 \\
\hline 15.00 & 0.13 & 7.28 & 2.62 & 2.36 & 2.32 & 2.27 & 2.27 & 19.12 & 77368 \\
\hline 16.00 & 0.11 & 5.92 & 2.12 & 1.90 & 1.86 & 1.81 & 1.80 & 15.40 & 62153 \\
\hline 17.00 & 0.09 & 4.82 & 1.72 & 1.54 & 1.50 & 1.45 & 1.44 & 12.46 & 50162 \\
\hline 18.00 & 0.07 & 3.94 & 1.40 & 1.25 & 1.21 & 1.17 & 1.15 & 10.12 & 40656 \\
\hline 19.00 & 0.06 & 3.23 & 1.15 & 1.02 & 0.98 & 0.95 & 0.93 & 8.25 & 33079 \\
\hline 20.00 & 0.05 & 2.66 & 0.94 & 0.83 & 0.80 & 0.77 & 0.75 & 6.75 & 27009 \\
\hline 21.00 & 0.04 & 2.19 & 0.77 & 0.68 & 0.65 & 0.63 & 0.61 & 5.54 & 22126 \\
\hline 22.00 & 0.03 & 1.81 & 0.64 & 0.56 & 0.54 & 0.51 & 0.50 & 4.56 & 18180 \\
\hline 23.00 & 0.0 & 1.50 & 0.53 & 0.46 & 0.44 & 0.42 & 0.41 & 3.7 & 14981 \\
\hline 24.00 & 0.02 & 1.25 & 0.44 & 0.38 & 0.36 & 0.35 & 0.33 & 3.11 & 12377 \\
\hline 25.00 & 0.02 & 1.04 & 0.36 & 0.32 & 0.30 & 0.29 & 0.27 & 2.58 & 10251 \\
\hline 26.00 & 0.02 & 0.87 & 0.30 & 0.26 & 0.25 & 0.24 & 0.23 & 2.15 & 8511 \\
\hline 27.00 & 0.01 & 0.73 & 0.25 & 0.22 & 0.21 & 0.20 & 0.19 & 1.79 & 7081 \\
\hline 28.00 & 0.01 & 0.61 & 0.21 & 0.18 & 0.17 & 0.16 & 0.15 & 1.49 & 5905 \\
\hline 29.00 & 0.01 & 0.51 & 0.18 & 0.15 & 0.14 & 0.14 & 0.13 & 1.25 & 4933 \\
\hline 30.00 & 0.01 & 0.43 & 0.15 & 0.13 & & 0.11 & 0.11 & & 4129 \\
\hline 31.00 & 0.01 & 0.36 & 0.12 & 0.11 & 0.10 & 0.09 & 0.09 & 0.88 & 3463 \\
\hline 32.00 & 0.01 & 0.30 & 0.10 & 0.09 & 0.08 & 0.08 & 0.07 & 0.74 & 2909 \\
\hline 33.00 & 0.00 & 0.26 & 0.09 & 0.08 & 0.07 & 0.07 & 0.06 & 0.62 & 2447 \\
\hline 34.00 & 0.00 & 0.22 & 0.07 & & 0.0 & & & & \\
\hline 35.00 & 0.00 & 0.18 & 0.06 & 0.05 & 0.0 & 0.05 & & & 1741 \\
\hline 36.00 & 0.00 & 0.16 & 0.05 & 0.05 & 0.04 & 0.04 & 0.04 & 0.37 & 1471 \\
\hline 37.00 & 0.00 & 0.13 & 0.05 & 0.04 & 0.04 & 0.03 & 0.03 & 0.32 & 1245 \\
\hline 38.00 & 0.0 & 0.11 & 0.04 & 0.03 & 0.0 & 0.03 & 0.0 & 0.2 & 1055 \\
\hline 39.00 & 0.00 & 0.00 & 0.03 & 0.03 & 0.03 & 0.02 & 0.02 & 0.13 & 723 \\
\hline 40.00 & 0.00 & 0.00 & 0.00 & 0.02 & 0.02 & 0.02 & 0.02 & & 392 \\
\hline 41.00 & 0.00 & 0.00 & 0.00 & 0.00 & 0.02 & 0.02 & 0.02 & 0.05 & 246 \\
\hline 42.00 & 0.00 & 0.00 & 0.00 & 0.00 & 0.00 & 0.0 & 0. & & 144 \\
\hline 43.00 & 0.0 & 0.00 & 0.00 & 0.00 & 0.00 & 0.00 & 0.0 & & 72 \\
\hline 44.0 & 0.00 & 0.00 & 0.00 & 0.00 & 0.00 & 0.00 & 0.00 & & 21 \\
\hline 45.00 & 0.00 & 0.00 & 0.00 & 0.00 & 0.00 & 0.00 & 0.00 & 0.0 & 0 \\
\hline 46.00 & 0.00 & 0.00 & 0.00 & 0.00 & 0.00 & 0.00 & & & 0 \\
\hline 47.0 & 0.0 & 0.00 & 0.00 & 0.00 & 0.00 & 0.00 & 0.00 & 0.00 & 0 \\
\hline 48.00 & 0.00 & 0.00 & 0.00 & 0.00 & 0.00 & 0.00 & 0.00 & 0.00 & 0 \\
\hline 49.00 & 0.00 & 0.00 & 0.00 & 0.00 & 0.00 & 0.00 & 0.00 & 0.00 & 0 \\
\hline 50 & 0.00 & 0.00 & 0.00 & 0.00 & 0.0 & 0.00 & 0.00 & 0.0 & \\
\hline & & & & & & $\mathrm{Vol} \mathrm{Hyd}$ & & $\mathrm{m} 3$ & $6 \mathrm{E}+06$ \\
\hline & & & & & & & & & \\
\hline & & & & & & $\begin{array}{l}\text { irrect } \\
\text { Rasio D }\end{array}$ & O/RE & $\begin{array}{l}\mathrm{mm} \\
\%\end{array}$ & $\begin{array}{l}104.27 \\
99.0 \%\end{array}$ \\
\hline
\end{tabular}

\section{Conclusions}

The unit hydrograph methods are still widely used tool in hydrologic analysis. These methods are simple, requiring only an easy determination of watershed characteristics, such as catchment area and river length. This paper, presents a new synthetic unit hydrograph computation method based on mass conservation principle. This mass conserving SUH calculation procedure, called ITB ITB SUH calculation method, has been implemented to develop ITB-1 and ITB-2 SUH. Our proposed method is flexible in adopting time lag and time to peak formula available in the literature. The method is applicable to any basic shape for synthetic unit hydrographs.

We derive a unit hydrograph calculation procedure in which the dimensionless synthetic unit hydrograph basic shape synthesized by using either a simple single function (ITB-1) or two simple functions (ITB-2). The peak discharge is then computed using terms involving time to peak and the ratio between catchment area and the area of unit hydrograph computed using trapezoidal rule. The computed time to peak and peak discharge value are then 
used to change the dimensionless unit hydrograph into dimensionalised unit hydrograph.

The derivation of peak discharge using our method is simple and easy to understand. Using such derivations, it is easy to teach students how to develop a synthetic unit hydrograph and corresponding peak discharge using different types of basic shapes suitable for unit hydrograph development. Unlike the peak discharge formula of other methods, which applies only to certain basic hydrograph shape (e.g. the Nakayasu peak discharge formula applies only to curves according Nakayasu etc), the proposed peak discharge formula applies for any basic hydrograph shape.

Finally some applications of the ITB SUH calculation method in computing design flood of small and medium size catchment are also presented. The results show that, although input data required by ITB-1 and ITB-2 synthetic unit hydrograph are simple and the calculation is easy, but the final results agree well with other methods developed earlier.

\section{Acknowledgement}

This research was supported by the Institute of Technology Bandung, through the Capacity Building Research Program 2010.

\section{References}

[1] Natakusumah D.K., Prosedure Umum Penentuan Hidrograf Satuan Sintetis Untuk Perhitungan Hidrograph Banjir Rencana, Water Resources Local Conference, Bandung, 11 August 2009.

[2] Natakusumah D.K., Hatmoko W., and Harlan D., A General Procedure for Developing a Synthetic Unit Hydrograph Based on Mass Conservation Principle. Development of ITB-1 and ITB-2 Synthetic Unit Hydrograph Method, International Seminar on Water-Related Risk, 15-17 July 2011.

[3] Natakusumah D.K., Hatmoko W., and Harlan D., Prosedure Umum Perhitungan Hidrograf Satuan Sintetis (HSS) dan Contoh Penerapannya Dalam Pengembangan HSS ITB-1 dan HSS ITB-2, Journal Teknik Sipil ITB, Vol. 18 No. 3 December 2011.

[4] Ramírez, J.A., 2000, Prediction and Modeling of Flood Hydrology and Hydraulics. Chapter 11 of Inland Flood Hazards: Human, Riparian and Aquatic Communities Eds., Ellen Wohl; Cambridge University Press.

[5] Wanielista, Martin., P., 1990, Hydrology Water Quantity and Quality Control, John Wiley \& Sons. Inc, Canada.

[6] Subramanya, K., 1984, Engineering Hydrology, Tata McGraw-Hill, New Delhi.

[7] Bedient, P.B. and Huber, W.C. (1992), Hydrology and Floodplain Analysis, 2nd Edition, Addison Wesley Publishing Company, New York. 